\title{
Radiological Environmental Protection for LCLS-II High Power Operation
}

\author{
James Liu *, Jan Blaha, Maranda Cimeno, Stan Mao, Ludovic Nicolas, Sayed Rokni, Mario Santana, Henry Tran \\ SLAC National Accelerator Laboratory, Menlo Park, CA, 95125, USA
}

\begin{abstract}
The LCLS-II superconducting electron accelerator at SLAC plans to operate at up to $4 \mathrm{GeV}$ and $240 \mathrm{~kW}$ average power, which would create higher radiological impacts particularly near the beam loss points such as beam dumps and halo collimators. The main hazards to the public and environment include direct or skyshine radiation, effluent of radioactive air such as ${ }^{13} \mathrm{~N},{ }^{15} \mathrm{O}$ and ${ }^{41} \mathrm{Ar}$, and activation of groundwater creating tritium. These hazards were evaluated using analytic methods and FLUKA Monte Carlo code. The controls (mainly extensive bulk shielding and local shielding around high loss points) and monitoring (neutron/photon detectors with detection capabilities below natural background at site boundary, site-wide radioactive air monitors, and groundwater wells) were designed to meet the U.S. DOE and EPA, as well as SLAC requirements. The radiological design and controls for the LCW systems [including concrete housing shielding for ${ }^{15} \mathrm{O}$ and ${ }^{11} \mathrm{C}$ circulating in $\mathrm{LCW},{ }^{7} \mathrm{Be}$ and erosion/corrosion products $\left({ }^{22} \mathrm{Na},{ }^{54} \mathrm{Mn},{ }^{60} \mathrm{Co},{ }^{65} \mathrm{Zn}\right.$, etc.) captured in resin and filters, leak detection and containment of LCW with ${ }^{3} \mathrm{H}$ and its waste water discharge; explosion from $\mathrm{H}_{2}$ build-up in surge tank and release of radionuclides] associated with the high power beam dumps are also presented.
\end{abstract}

\section{Introduction}

SLAC National Accelerator Laboratory (SLAC) is designing the LCLS-II hard X-ray free-electron-laser facility, which utilizes a new superconducting (SC) electron linac for operation with a maximum beam of 4 $\mathrm{GeV}, 240 \mathrm{~kW}$ average power and $\mathrm{MHz}$ capability. The LCLS-II high power operation will create higher radiological impacts to the workers, public and environment, particularly near the beam loss points such as beam dumps and halo collimators.

The main impacts to the public and environment include direct or skyshine neutron and photon radiation, effluent of radioactive air (e.g., ${ }^{13} \mathrm{~N},{ }^{15} \mathrm{O}$ and ${ }^{41} \mathrm{Ar}$ ), and activation of groundwater (mainly tritium). Radiological design and controls for Low Conductivity Water (LCW) systems is one of the main subjects for protection of the workers, public and environment. The assessment, controls and monitoring of these hazards to satisfy the U.S. Department of Energy (DOE) and SLAC requirements are described.

\section{Protection of Public and Environment}

\subsection{LCLS-II facility}

SLAC has an existing 3-km-long underground linac tunnel. Figure 1 shows the LCLS-II layout from SC linac along Sector 0 to 10 to beam switching in BSY (via a spreader line), either dumping all or partial of the electrons at the BSY dump or directing beams through two variable-gap undulators (SXU and HXU) to generate hard and soft X-rays. The electrons beams are then bended to two main dumps (EBD). The BSY dump and EBD dumps, as well as halo collimators along linac and BSY, are the main beam loss points.

Table 1 summarizes the normal electron beam losses estimated by LCLS-II [1]. Maximum power and average power (considering use factors) are used to evaluate the radiological hazards to workers and public/environment, respectively.

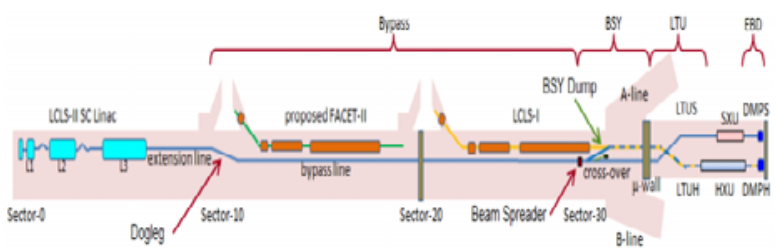

Figure 1. LCLS-II accelerator and beamline layout.

Table 1. LCLS-II main electron beam loss points.

\begin{tabular}{|c|c|c|c|}
\hline & Linac-BSY & BSY & Dump Hall \\
\hline Component & $\begin{array}{c}\text { Each Halo } \\
\text { Collimator }\end{array}$ & Dump & $\begin{array}{c}2 \mathrm{EBD} \\
\text { dumps }\end{array}$ \\
\hline Maximum Power & $32 \mathrm{~W}$ & $250 \mathrm{~kW}$ & $2 \times 120 \mathrm{~kW}$ \\
\hline Average Power & $13 \mathrm{~W}$ & $90 \mathrm{~kW}$ & $27+48 \mathrm{~kW}$ \\
\hline
\end{tabular}

\subsection{Skyshine radiation}

Because most of LCLS-II accelerator housings are deep underground, skyshine radiation to the public residing near SLAC site boundary is dominated by high-energy neutrons penetrating the 1.2-1.8 meter thick concrete roofs of the only aboveground section BTH.

With a total beam loss limited to $75 \mathrm{~W}$ by SLAC Long Ion Chambers inside BTH, the maximum skyshine dose to the public was calculated to be $6 \mu \mathrm{Sv} / \mathrm{y}$ at $500 \mathrm{~m}$ from BTH with the SKYSHINE code [2]. This meets the SLAC shielding design goal of $50 \mu \mathrm{Sv} / \mathrm{y}$ per facility within SLAC.

The skyshine radiation will be monitored continuously with eight stations around SLAC site boundary with radiation detectors sensitive to detect $1 \mathrm{nSv} / \mathrm{h}$ and 10 $\mathrm{nSv} / \mathrm{h}$ for neutrons and photons, respectively [3].

\footnotetext{
* Corresponding author: james@slac.stanford.edu
} 


\subsection{Radioactive air effluent}

The dose to the public from the exposure pathway of radioactive air effluent is dictated by the radioactive air with ${ }^{11} \mathrm{C},{ }^{13} \mathrm{~N},{ }^{15} \mathrm{O}$ and ${ }^{41} \mathrm{Ar}$ released from the accelerator housing. For LCLS-II, high beam loss points are heavily shielded locally for the protection of groundwater and workers from induced activity. In this case, FLUKA calculations [4] show that the production of radioactive air is dominated by the small air volume between dump (or collimator) and local shielding, that should be minimized. Table 2 gives the saturation activity of radioactive air at LCSL-II, which is dominated by 240 $\mathrm{kW}$ beam loss at BSY dump with local shielding [4].

SLAC accelerator housing will have no forced ventilation during beam on, but the housing is not tightly sealed and it will have natural air leakage. With the calculated saturation activity (which can be reached with a few hours of beam on) and the natural air leakage rates, annual activity releases $(\mathrm{Bq} / \mathrm{y})$ can be estimated. The doses to the Maximum Exposed Individual (MEI) of public can then be calculated using the DOE-approved CAP-88 analytic code, considering the population data and annual average meteorological data in Bay area [5]. Table 3 shows that the maximum annual dose to the MEI from LCLS-II is $390 \mathrm{nSv} / \mathrm{y}$ from BSY dump operation. This is lower than the design goal of $1 \mu \mathrm{Sv} / \mathrm{y}$ to MEI from each air release point (such that there are no requirements for continuous air monitoring) and is much lower than the design limit of $100 \mu \mathrm{Sv} / \mathrm{y}$.

Periodic confirmatory measurements of the radioactive air production and concentration inside housing will be conducted in-situ using Eberline AMS-4 noble gas monitors, which can detect down to 0.1 Derived Air Concentration [3] of ${ }^{13} \mathrm{~N}$ and ${ }^{41} \mathrm{Ar}$.

Table 2. Production of radioactive air at LCLS-II.

\begin{tabular}{|c|c|c|c|}
\hline $\begin{array}{c}\text { Saturation Activity } \\
\text { (MBq) }\end{array}$ & $\begin{array}{c}\text { Linac } \\
\text { Collimator }\end{array}$ & $\begin{array}{c}\text { BSY } \\
\text { Dump }\end{array}$ & $\begin{array}{c}\text { EBD } \\
\text { Dumps }\end{array}$ \\
\hline $\begin{array}{c}\text { Maximum Power } \\
\text { (kW) }\end{array}$ & $\begin{array}{c}1 \\
\text { (no shielding) }\end{array}$ & 240 & $2 \times 120$ \\
\hline${ }^{11} \mathrm{C}$ & 33 & 225 & 13.5 \\
\hline${ }^{13} \mathrm{~N}$ & 57 & 496 & 40.7 \\
\hline${ }^{15} \mathrm{O}$ & 61 & 326 & 18.0 \\
\hline${ }^{41} \mathrm{Ar}$ & 26 & 537 & 2.41 \\
\hline
\end{tabular}

Table 3. Annual doses to the MEI of public from radioactive air effluent at LCLS-II.

\begin{tabular}{|c|c|c|c|}
\hline $\begin{array}{c}\text { Dose to MEI } \\
(\mathbf{n S v} / \mathbf{y})\end{array}$ & $\begin{array}{c}\text { Linac } \\
\text { Collimator }\end{array}$ & $\begin{array}{c}\text { BSY } \\
\text { Dump }\end{array}$ & $\begin{array}{c}\text { EBD } \\
\text { Dumps }\end{array}$ \\
\hline $\begin{array}{c}\text { Average Power } \\
(\mathbf{k W})\end{array}$ & $\begin{array}{c}1 \\
\text { (no shielding) }\end{array}$ & 90 & 75 \\
\hline${ }^{11} \mathrm{C}$ & 9.3 & 64 & 0.57 \\
\hline${ }^{13} \mathrm{~N}$ & 12.7 & 111 & 1.38 \\
\hline${ }^{15} \mathrm{O}$ & 3.9 & 22 & 0.27 \\
\hline${ }^{41} \mathrm{Ar}$ & 13.5 & 193 & 0.17 \\
\hline
\end{tabular}

\subsection{Groundwater activation}

The main concern of radiological impacts to environmental media is the potential activation of soil and groundwater near the beam loss points from highenergy neutrons (over $100 \mathrm{MeV}$ ) penetrating through heavy local and housing shielding. The regulatory requirement for groundwater protection is that there should be no impact to groundwater. Therefore, the shielding design goal for LCLS-II is that there should be no detectable activity in groundwater. Because of its high production cross section and high leachability from soil to groundwater, tritium is the main radionuclide of concern for groundwater protection. The design goal [3] is therefore that potential tritium concentration in groundwater should be less than the detection limit of 37 $\mathrm{Bq} / \mathrm{L}$ for ${ }^{3} \mathrm{H}$ required by the U.S. Environmental Protection Agency.

Extensive local shielding has been added to BSY and EBD dumps to reduce the groundwater activation $[6,7]$. Due to limited space, the shielding was optimized based on calculations using FLUKA Monte Carlo code.

Figure 2 shows the groundwater activation at the LCLS-II EBD dumps. The groundwater table is located at about $10 \mathrm{~m}$ below the dump such that direct activation of groundwater is smaller than the indirect path in which the most irradiated rain water $1-\mathrm{m}^{3}$ volume flows at the worst drift speed from earth surface to groundwater table. With a $30 \%$ leachability and conservatively assuming no diffusion and no dilution in soil and groundwater, the ${ }^{3} \mathrm{H}$ concentration in groundwater table is estimated to be 26 $\mathrm{Bq} / \mathrm{L}$ for $75 \mathrm{~kW}$ average power. For ALARA purpose, geo-membrane is considered as an option to further reduce the tritium concentration.

Several groundwater monitoring wells will be added near the BSY and EBD dumps, as well as Linac collimators with beam losses more than $10 \mathrm{~W}$, to the existing $\sim 100$ wells at SLAC [3].

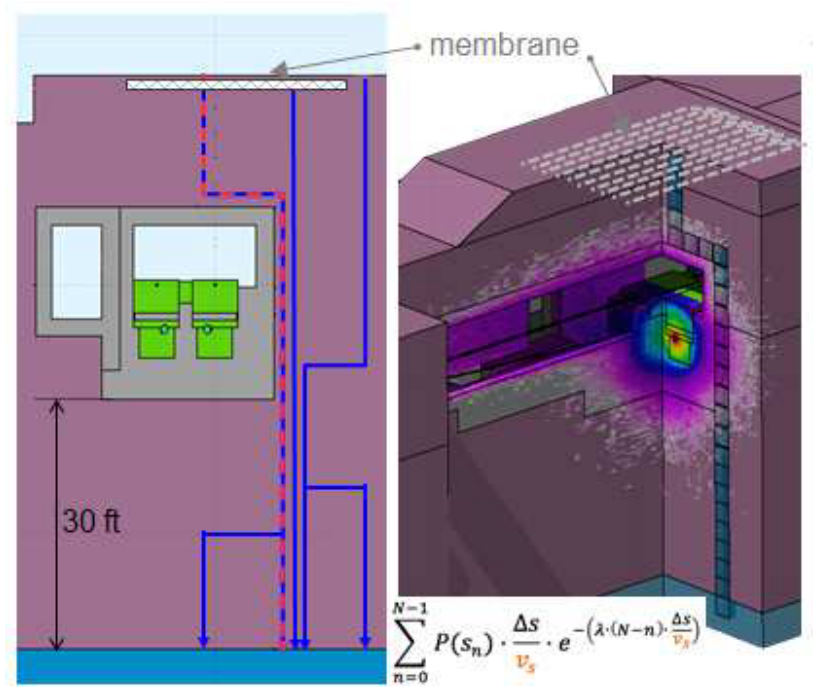

Figure 2. Activation of Groundwater located at $10 \mathrm{~m}$ below the LCLS-II EBD dumps. 


\section{Radiological design and controls for LCW system}

A large amount of LCW is needed to cool high-power dumps and collimators, which will activate the LCW and any erosion/corrosion products flowing with LCW. Figure 3 shows a typical LCW system for a high power dump at SLAC, which include the LCW and its piping, surge tank, resin tanks, filter bottles, heat exchanger inside a concrete housing [8]. Main radiological hazards for a LCW system that need to be addressed include: ${ }^{3} \mathrm{H}$ in water, ${ }^{15} \mathrm{O}$ and ${ }^{11} \mathrm{C}$ in water, ${ }^{7} \mathrm{Be}$ and erosion/corrosion products $\left({ }^{22} \mathrm{Na},{ }^{54} \mathrm{Mn},{ }^{60} \mathrm{Co},{ }^{65} \mathrm{Zn}\right.$, etc. $)$ captured in resin and filters, and potential explosion from $\mathrm{H}_{2}$ build-up in surge tank. The mitigation measures include [8]: shielding of concrete housing and underground piping from ${ }^{15} \mathrm{O}$ and ${ }^{11} \mathrm{C}$ in LCW, shielding of concrete housing from ${ }^{7} \mathrm{Be}$ and erosion/corrosion products in resin/filters, access controls to housing (locked door and interlocked to radiation monitoring), detection and containment of LCW leakage, management of discharge of waste water with ${ }^{3} \mathrm{H}$ into sewer, using hydrogen recombiner to reduce $\mathrm{H}_{2}$ build-up, and utilization of remote or automatic systems for the exchanges and disposal of resin and filters to minimize worker exposure and accelerator operational impacts.

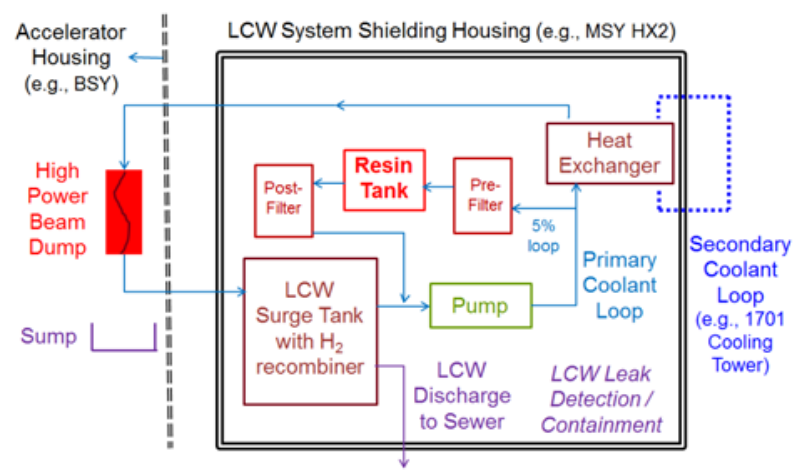

Figure 3. LCW system for a LCLS-II high power dump.

Table 4 summarizes the induced activities in the LCW system components for BSY and EBD dumps, estimated using FLUKA code or SLAC empirical data [9]. The BSY dump has small aluminum balls mixed in 39-liter of water followed by a solid $\mathrm{Cu}$ end-cap. Each EBD dump is an aluminum core plus tungsten end-cap that is surface cooled with 6.6-liter water. It is clear that the BSY dump (a volume-cooled dump) will have much higher induced activity than that of the EBD dump (a surface-cooled dump); 150 times in this design.

To meet the shielding design goal of $1 \mathrm{mSv} / \mathrm{y}$, the concrete housing needs to have $60 \mathrm{~cm}$ concrete walls (45 $\mathrm{cm}$ ceiling) and the underground pipes need to shielded with $100 \mathrm{~cm}$ soil; which is dictated by ${ }^{15} \mathrm{O}$ and ${ }^{11} \mathrm{C}$ flowing with LCW, that would decay within 1-2 hours after beam is off. For erosion/corrosion products (dictated by ${ }^{22} \mathrm{Na}$ or ${ }^{60} \mathrm{Co}$ ) and ${ }^{7} \mathrm{Be}$ captured in resin, $45 \mathrm{~cm}$ concrete walls are needed for shielding when workers access the housing after beam is off. Other key LCW components include a locked door interlocked with a photon radiation detector, three 100 -gallon resin tanks with remote resin exchange features, vented surge tank with hydrogen recombiner, LCW pressure sensors to detect leak and sump to contain leak, and a controlled, direct LCW discharge piping to sewer.

Table 4. Induced activities in LCW system components.

\begin{tabular}{|c|c|c|}
\hline & BSY Dump & EBD Dumps \\
\hline${ }^{3} \mathrm{H}$ saturation activity & $\begin{array}{l}510 \mathrm{GBq} \\
\text { at } 90 \mathrm{~kW}\end{array}$ & $\begin{array}{l}3.3 \mathrm{GBq} \\
\text { at } 76 \mathrm{~kW}\end{array}$ \\
\hline $\begin{array}{c}{ }^{7} \text { Be saturation activity } \\
\text { at } 250 \mathrm{~kW}\end{array}$ & $200 \mathrm{GBq}$ & $1.4 \mathrm{GBq}$ \\
\hline $\begin{array}{l}{ }^{15} \mathrm{O} \text { and }{ }^{11} \mathrm{C} \\
\text { saturation activity } \\
\text { at } 250 \mathrm{~kW}\end{array}$ & $\begin{array}{c}2850 \mathrm{GBq}{ }^{15} \mathrm{O} \\
700 \mathrm{GBq}{ }^{11} \mathrm{C} \\
\& 0.56 \mathrm{~Sv} / \mathrm{h} \\
\text { at } 1 \mathrm{~m} \\
\end{array}$ & $\begin{array}{l}19 \mathrm{GBq}^{15} \mathrm{O}, \\
3.7 \mathrm{GBq}{ }^{11} \mathrm{C} \\
\& 3.5 \mathrm{mSv} / \mathrm{h} \\
\text { at } 1 \mathrm{~m} \\
\end{array}$ \\
\hline $\begin{array}{c}{ }^{22} \mathrm{Na},{ }^{54} \mathrm{Mn},{ }^{60} \mathrm{Co},{ }^{65} \mathrm{Zn} \\
\text { maximum activities } \\
\text { estimated from } \\
\text { historical data of } \\
\text { similar LCW systems } \\
\text { at SLAC }\end{array}$ & $\begin{array}{l}5 \mathrm{mSv} / \mathrm{h} \text { at } 1 \mathrm{~m} \\
\text { from two } 400-\mathrm{L} \\
\text { resin tanks } \\
\text { (equivalent to } \\
15 \mathrm{GBq}{ }^{60} \mathrm{Co} \text { ) }\end{array}$ & $\begin{array}{l}50 \mu \mathrm{Sv} / \mathrm{h} \text { at } 1 \mathrm{~m} \\
\text { from two } 400-\mathrm{L} \\
\text { resin tanks } \\
\text { (equivalent to } \\
0.15 \mathrm{GBq}{ }^{60} \mathrm{Co} \text { ) }\end{array}$ \\
\hline
\end{tabular}

\section{Conclusions}

LCLS-II beam power is at least 2 orders of magnitude higher than LCLS-I. Radiological protection for the public, environment and workers is more challenging, considering that there are less safety margin and the constraints of building LCLS-II on existing LCLS-I accelerator housing and infrastructure configuration. The main issues of hazard evaluation and controls for BSY dump, EBD dumps, and halo collimators are being addressed to meet the regulatory and SLAC requirements.

\section{References}

1. J. Welch, SLAC LCLS-II Physics Requirement Document, LCLSII-2.7-PR-0079-R1, (2015)

2. S. Mao, SLAC Memo, RP-RPG-131105-MEM-01, (2013)

3. J. Liu, SLAC LCLS-II Physics Requirement Document, LCLSII-1.2-PR-0265-R0, (2014)

4. L. Nicolas, SLAC Memo, RP-RPG-140806-MEM01, (2014)

5. H. Tran, SLAC Technical Note, RP Note 15-05, (2015)

6. L. Nicolas, SLAC Technical Note, RP Note 15-06, (2015)

7. M. Santana, SLAC LCLS-II Physics Requirement Document, LCLSII-1.2-PR-0100-R0, (2014)

8. J. Liu, SLAC LCLS-II Physics Requirement Document, LCLSII-1.2-PR-0211-R0, (2014)

9. J. Blaha, SLAC Technical Note, RP Note 15-19, (2016)

*This work is supported by the U.S. DOE, Office of Science, Office of Basic Energy Sciences, under Contract No. DEAC02-76SF00515. 